\title{
Study of some biological parameters of the oil palm tree leaf miner, Coelaenomenodera lameensis (Coleoptera: Chrysomelidae, Hispinae) in a semi-controlled environment
}

\author{
Ahou Cyprienne KOUASSI ${ }^{1,2 *}$, Akpa Alexandre Moïse AKPESSE ${ }^{1}$, \\ Assiénin Hauverset N'GUESSAN ${ }^{2}$, N'Klo HALA ${ }^{2}$, Kouakou Hervé KOUA ${ }^{1}$ and \\ Kouassi Philippe KOUASSI ${ }^{1}$
}
${ }^{1}$ Laboratory of Natural Environment and Biodiversity Conservation, University Félix Houphouët-Boigny, UFR Biosciences Abidjan, Côte d'Ivoire, 22 BP 582 Abidjan 22, Côte d'Ivoire.
${ }^{2}$ National Agronomic Research Center (La Mé Station), 13 BP 989 Abidjan 13, Côte d'Ivoire.
*Corresponding author; E-mail: ahoucypri@gmail.com; Tel.: + 2250709763064

\begin{tabular}{lll}
\hline Received: 25-08-2021 & Accepted: 16-12-2021 & Published: 31-12-2021 \\
\hline
\end{tabular}

\begin{abstract}
The oil palm tree is the first source of fatty substances of vegetable origin in the world. However, its cultivation is strongly threatened by damage from Coelaenomenodera lameensis. The present study aimed at promotion a good knowledge of its biology in order to better manage its populations. Thus, some biological parameters of this pest were studied by means of cage breeding (September 2015-December 2017) on an plot of La Mé station of National Agronomic Research Center located $30 \mathrm{~km}$ North-East of Abidjan in Côte d'Ivoire. The results revealed that the development of $C$. lameensis passes successively through stages egg, larva, nymph, internal adult and external adult stages. Also, the female lays an average of $137.48 \pm 62.04$ eggs and the number of individuals gradually decreases from egg stage to adult stage. The average life cycle length was $94.5 \pm 7.94$ days with a sex ratio of $1.34 \pm 0.25$ in favor of males. In addition, the mean lifespan was shorter in females than in males with respectively, $103.24 \pm 10.25$ days and $127.34 \pm 21.41$ days. All these parameters constitute potential indicators of $C$. lameensis biology and could help to put in place good strategies for control of its populations. (C) 2021 International Formulae Group. All rights reserved.
\end{abstract}

Keywords: Elaeis guineensis, main pest of oil palm tree, life cycle, reproductive capacities, sex-ratio, lifetime.

\section{INTRODUCTION}

The oil palm tree Elaeis guineensis is cultivated for its oils, palm oil and palm kernel oil. It is the number one source of fatty substances of plant origin in the world (USDA, 2015). These oils, especially palm oil, occupy a prominent place in the exchanges, consumption of fats (Aholoukpè et al., 2013), in the manufacture of many agri-food products, cosmetics and biofuels (Rival, 2020). In Côte d'Ivoire, the production of crude palm oil is estimated at about 500.000 tons (Bessou et Dubos, 2020). This makes the country the second largest producer of palm oil in Africa (after Nigeria). Despite this, Ivorian production is insufficient given the ever-increasing needs and the many uses of palm oil (cosmetic and 
agro-food industry) (Cucumel, 2020). Therefore, an increase in production is necessary.

However, oil palm cultivation is facing attacks from many pests including Coelaenomenodera lameensis, (Coleoptera: Chrysomelidae, Hispinae) which is the most formidable insect pest in West Africa and particularly in Côte d'Ivoire (Koua et al., 2010; Tano, 2012; Akpesse et al., 2015). Its damage can cause a drop in production of 30 to $50 \%$ over a period of 2 to 3 years (Mariau, 2001; Tano et al., 2013). A good control strategy against this pest requires first a perfect knowledge of its biological parameters. It is in this context that this study was carried out with the objective of determining some biological parameters of $C$. lameensis.

\section{MATERIALS AND METHODS \\ Study site}

This study was carried out from September 2015 to December 2017 at La Mé experimental station of the National Center for Agronomic Research located $30 \mathrm{~km}$ North-East of Abidjan, on the road leading to Alepé ( in Côte d'Ivoire).

\section{Materials}

To determine the biological parameters of $C$. lameensis, rearing was carried out using cages with small sleeves and cages with large sleeves. Each type of cage was made using a transparent white muslin fabric with 600 microns of mesh, a rectangular metal frame 32 $\mathrm{cm}$ long and $12 \mathrm{~cm}$ wide (small cages), 2 frames metal circulars $80 \mathrm{~cm}$ in diameter (large cages), cotton wool, a roll of wire and 2 forks (Figure 1).

\section{Experimentations}

After the cages were made, adults of $C$. lameensis were captured on an infested plot. These were then sexed and paired in cages with large sleeves previously placed on the study plot. These were placed on 25 healthy palms selected at random (one cage/palm tree). Each cage is placed precisely on a row 17 palm and has 64 healthy leaflets. A total of 50 pairs were put in each cage. All adults were removed from the cages after spawning. The cages were followed until new adults emerged. The new emerged adults were also sexed and reared in cages with small sleeves, each placed on a palm tree precisely on a row 17 palm. Each cage has three leaflets free from any pest attack. Indeed, 4 small cages are placed each month for each parameter evaluated. Once the cages have been placed, adults from the first breeding are put in pill organizers per sex and in groups of 5 , and then introduced into the cages at the rate of 5 pairs/cage. The date of caging of the insects was recorded and a daily check was carried out in order to know the dates of mating, laying, emergence of larvae, nymphs and adults. The adults were removed from the cages after spawning.

Temperature and relative humidity were recorded daily throughout the study.

\section{Parameters studied Reproductive capacities}

Reproductive capacities express the reproductive modalities of the insect. They were expressed here by the average number of oviposition sites per leaflet, the average number of eggs per female, the average number of eggs per oviposition site, the average number of individuals (eggs, larvae, nymphs and adults) per leaflet and the average number of individuals (larvae, nymphs and adults) per gallery. Observation of leaflets at different stages (eggs, larvae, nymph and adults) was used to determine these reproductive capacities. The eggs are laid on the underside of the leaflets and visible on the upper side of the leaflets. They are protected by a fibrous mass resulting from the mixture of feces and a substance emitted by the female at the time of oviposition, which hardens in the open air, cements the egg. The observation of the eggs was thus made by scraping the upper epidermis of the leaflet with a pair of forceps. The larvae, nymphs and adults are lodged in protective galleries visible on the leaflets. To observe them, these galleries were opened with forceps. 
Reproductive capacities of $C$. lameensis were determined by using the following formulas:

- Average number of laying place per leaflet (Avg Lp/NI)

$$
\operatorname{Avg~Lp/Nl}=\left(\sum_{1}^{\mathrm{n}}\left(\frac{\mathrm{NLp}}{\mathrm{Nl}}\right)\right)
$$

With NLp: Number of laying place et Nl: Number of leaflets.

- Average number of individuals per leaflet (Avgi/l).

$\operatorname{Avgi~}(\mathrm{x}) / \mathrm{l}=\left(\sum_{1}^{\mathrm{n}}\left(\frac{\mathrm{Ni}(\mathrm{x})}{\mathrm{Nl}}\right)\right.$

With Ni (x): Number of individuals at stage (x), $\mathbf{x}$ : Stage considered (larva or nymph or internal adult) and NI: Number of leaflets.

- Average number of eggs per female (Avg eggs / female).

$$
\text { Avg eggs/female }=\left(\sum_{1}^{\mathrm{n}}\left(\frac{\mathrm{No}}{\mathrm{Nf}}\right)\right.
$$

With No: Number of eggs and Nf: Number of females.

- Average number of galleries per leaflet (Avg gal/l).

$$
\operatorname{Avg} \text { gal } / \mathbf{l}=\left(\sum(\text { Ngal Nl })\right.
$$

With Ngal: Number of galleries and Nl: Number of leaflets.

- Average number of individuals per gallery (Avgi (x)/gal).

$$
\operatorname{Avgi}(\mathrm{x}) / \mathrm{gal}=\left(\sum_{1}^{\mathrm{n}}\left(\frac{\mathrm{Ni}(\mathrm{x})}{\mathrm{Ngal}}\right)\right.
$$

With Ni (x): Number of individuals at stage (x), $\mathbf{x}$ : Stage considered (larva or nymph or internal adult) and Ngal: Number of galleries.

\section{Development cycle length}

- Average incubation time (Di)

The average incubation time is the number of days between the observation of the eggs and the emergence of the first larvae. It was determined from the date of observation of eggs and first larvae (L1). The average incubation time was obtained according to the formula:

$$
\text { Di (days) }=\left(\sum_{1}^{n}\left(\frac{\mathrm{di}}{\mathrm{ne}}\right)\right.
$$

With di: Time taken for an egg to hatch and ne: Number of eggs.

- Average duration of larval development $(D L)$

The different larval stages were distinguished by using the dimensions of the larval cephalic capsules. The average duration of larval development is the number of days elapsed from the observation of the first larvae until the emergence of the nymphs. It was obtained by adding the mean duration of development of the 1st larval stage (DL1), of the 2nd larval stage (DL2), of the 3rd larval stage (DL3) and of the 4th larval stage (L4) as presented by the formula below:

\section{DL $($ days $)=$ DL1 + DL2 + DL3 + DL4}

- Average nymph development time (Dn) The mean nymph development time is the number of days from observation of the nymph stage to observation of the internal adult. It was obtained according to the formula below:

$$
\text { Dn (days) }=\left(\sum_{1}^{n}\left(\frac{\mathrm{dn}}{\mathrm{ny}}\right)\right.
$$

With dn: Time taken for a nymph to transform into an internal adult and ny: Number of nymphs observed. 
- Average development time of internal adult (Dadi)

The average developmental time of the internal adult is the number of days that elapse between the observation of the internal adult and the external adult. As soon as the internal adults were observed, 24 of them (12 males and 12 females) were isolated from the galleries (using a flexible clamp) and placed in 2 other cages at the rate of 12 adults of the same sex per cage. The elytra of these adult insects were then touched 3 times a day (at 7 a.m., at 12 hours (middle day) and at 6 p.m.) to assess their rigidity. Thus, the average developmental time of the internal adult was determined using the formula below:

Dadi (days) $=\sum_{1}^{n}$ dadi $/$ nadi

With dadi: Number of days taken by an internal adult to transform into an external adult and nadi: Number of internal adults.

- Average duration of pre-copulation (Dprecop)

The average duration of pre-copulation is the number of days it takes for an external adult to have their first copulation. Thirty pairs of adults outpatients were each placed in a cage with a small sleeve and were observed each day for the date of first copulation. Thus, the mean duration of pre-copulation was determined from the date of emergence of external adults and the date of first copulation.

$$
\text { Dprecop (days) }=\left(\sum_{1}^{n}\left(\frac{\mathrm{nd}}{\mathrm{nc}}\right)\right.
$$

With nd : Number of days taken by an external adult before mating with another of opposite sex and nc: Number of couples.

- Average duration of pre-oviposition (Dpreop)

Pre-oviposition is the period between the first copulation and the laying. The mean duration of pre-oviposition was determined

$$
\text { Dpreop (days) }=\left(\sum_{1}^{n}\left(\frac{\mathrm{nd}}{\mathrm{nf}}\right)\right.
$$

from the date of observation of the first copulation and that of the first spawning. It was determined using the following formula: With nd: Number of days that a fertilized female takes before laying eggs and nf: Number of females.

- Total development cycle time (DT)

The total duration of $C$. lameensis development cycle was obtained by adding the duration of incubation (Di), the different larval stages (DL), the nymph (Dn), the internal adult (Dadi), pre-copulation (Dpreco) and preoviposition (Dpreop) according to the formula below :

$$
\mathrm{DT}=\mathrm{Di}+\mathrm{DL}+\mathrm{Dn}+\text { Dadi }+ \text { Dpreco }+ \text { Dpreop }
$$

\section{Sex ratio}

The sex ratio is the ratio between the number of males and females emerged from the offspring of a couple. All farmed adults were sexed. This made it possible to determine the value of the sex ratio (SR). It was obtained according to the formula below:

$$
\mathrm{SR}=\left(\sum_{1}^{\mathrm{n}}\left(\frac{\mathrm{Nma}}{\mathrm{Nfem}}\right)\right.
$$

With Nma: Number of males and Nfem: Number of females.

\section{Lifetime}

Lifetime (DLt) is the number of days from observation of external adults until their death. Thirty pairs of external adults from the farm were trained and each put into a cage with a large sleeve. Thus, checks were carried out every day and the dead insects were gradually removed from the cages. Likewise, the live insects were transferred to a new cage whenever the leaflets were found to dry out. This allowed them to have food all the time. The number of days elapsed from the caging of the insects until their death was then determined according to the formula:

$$
\mathrm{DLt}=\sum_{1}^{\mathrm{n}}\left(\frac{\mathrm{t}}{\mathrm{n}}\right)
$$

With t: Time taken by an insect before dying and $\mathbf{n}$ : Number of insects. 

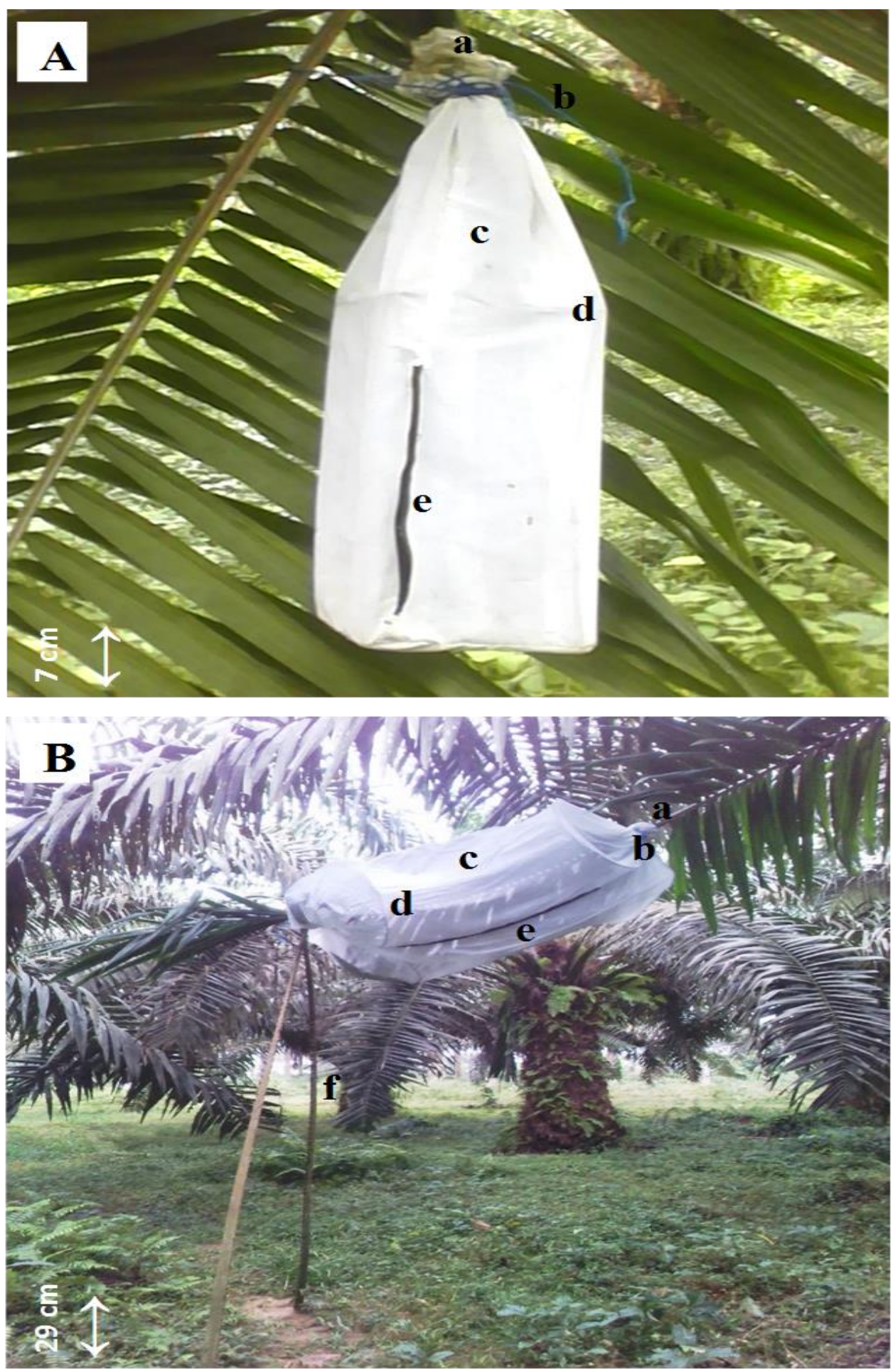

Figure 1: Breeding cages.

A : Small sleeve cage, B : Large sleeve cage ; a : Hydrophilic cotton; b : Thread ; $\mathbf{c}:$ Muslin fabric ; d : Metallic armature (internal); e : Adhesive band ; $\mathbf{f}:$ Oil palm tree rachis. 


\section{RESULTS}

\section{Reproductive capacities}

During its lifetime, a female Coelaenomenodera lameensis laid an average of $137.48 \pm 62.04$ eggs. After one day of oviposition, an average of $22.08 \pm 9.03$ oviposition sites can be observed on an oil palm leaflet. Thus, an oviposition site can contain an average of $6.35 \pm 4.51$ eggs.

During the development of $C$. lameensis, the number of individuals decreases gradually from one stage to another. Thus, for 20 pairs of insects an oil palm leaflet may contain, on average, $227.13 \pm 89.25$ eggs, $44.38 \pm 12.46$ larvae, $33.42 \pm 8.81$ nymph and $23.38 \pm 8.27$ adults (Figure 2). Similarly, the number of galleries that can be observed on a leaflet being $5.23 \pm 2.74$ and a gallery can contain on average, $6.64 \pm 2.72$ larvae, $3.23 \pm$ 2.05 nymphs, $3.02 \pm 1.58$ adult (Figure 3 ).

\section{Duration of the development cycle of Coelaenomenodera lameensis}

The development of $C$. lameensis proceeds successively through the egg, larva, nymph and adult stages. The average length of the egg is $0.75 \pm 0.09 \mathrm{~mm}$. The average length of the larval stages (including cephalic capsule) is $1.35 \mathrm{~mm} \pm 0.42$ in stage 1 larva (L1), $1.85 \pm$ $0.73 \mathrm{~mm}$ in stage 2 larva, $2.25 \pm 1.09 \mathrm{~mm}$ in stage 3 larva and $3.86 \pm 1.15 \mathrm{~mm}$ in stage 4 larva. The average length of the nymph is 5.15 $\pm 0.69 \mathrm{~mm}$. The adult has an average length of $5.51 \pm 0.41 \mathrm{~mm}$.

The life cycle of $C$. lameensis is divided into 4 different phases which are precopulation, pre-oviposition, larval development and nymphal development.

\section{Pre-copulation time}

Mating between male and female $C$. lameensis occurs after a pre-copulation period of $3.5 \pm 0.51$ days (Table 1 and Figure 4).

\section{Pre-oviposition time}

After mating, the female of $C$. lameensis lays her eggs after $7 \pm 0.44$ days (Table 1 and Figure 4).

\section{Incubation time}

Egg hatching, characterized by the emergence of larvae, occurs after an average incubation period of $20.5 \pm 1.11$ days (Table 1 and Figure 4).

\section{Duration of larval development}

When the eggs hatch, the first stage larvae are observed. As they develop, these larvae become respectively stage 2, 3 and 4 larvae. These larvae were differentiated by the dimensions of the cephalic capsules. Thus, the average width of the cephalic capsule of the larvae is $0.27 \pm 0.03 \mathrm{~mm}, 0.42 \pm 0.04 \mathrm{~mm}, 0.61$ $\pm 0.03 \mathrm{~mm}$ and $0.82 \pm 0.17 \mathrm{~mm}$ for stages 1,2 , 3 and 4 respectively. Similarly, the average length of the cephalic capsule of the larvae was $0.24 \mathrm{~mm} \pm 0.04,0.55 \mathrm{~mm} \pm 0.11,0.77 \mathrm{~mm} \pm$ 0.13 and $1.13 \mathrm{~mm} \pm 0.41$ for stages $1,2,3,4$ respectively. The passage from one stage to another is done by molts larvae. The duration of development was on average $12.5 \pm 1.07$ days in the L1 larva, $9.5 \pm 0.96$ days in the L2 larva, $10.5 \pm 1.19$ days in the L3 larva and 14.5 \pm 1.08 days in the L4 larva. The development time of L4 larvae was therefore longer than that of the other stages (Table 1 and Figure 4).

\section{Duration of nymph development}

In $C$. lameensis, the development of stage 4 larvae results in the emergence of the nymph through a molt called the pupal molt. The development of the nymph ends with a molt called an imaginal molt. This imaginal molt thus results in the emergence of the internal adult (still housed in the gallery) which occurs after $13.5 \pm 0.86$ days (Table 1 and Figure 4).

\section{Developmental period of the internal adult}

The internal adult transforms into an external adult and leaves the tunnel after a period of $3 \pm 0.69$ days (Table 1 and Figure 4).

\section{Total development cycle time}

The total developmental cycle time of C. lameensis from egg incubation to emergence in the external adult was $91 \pm 7.4$ days. The total development time of $C$. lameensis from egg-to-egg incubation (full cycle) was $94.5 \pm$ 7.91 days (Table 1 and Figure 4).

\section{Sex-ratio and Lifetime}

One oil palm leaflet can contain on average, $12.82 \pm 3.62$ males and $9.55 \pm 1.9$ females of $C$. lameensis. The number of males is statistically higher than the number of females $(\mathrm{P}<0.05)$, representing a sex ratio of $1.34 \pm 0.25$ (Figure 5). C. lameensis males live longer (127.34 \pm 2.41 days) than females $(103.24 \pm 10.25$ days $)(\mathrm{P}<0.05)$ (Figure 6) 


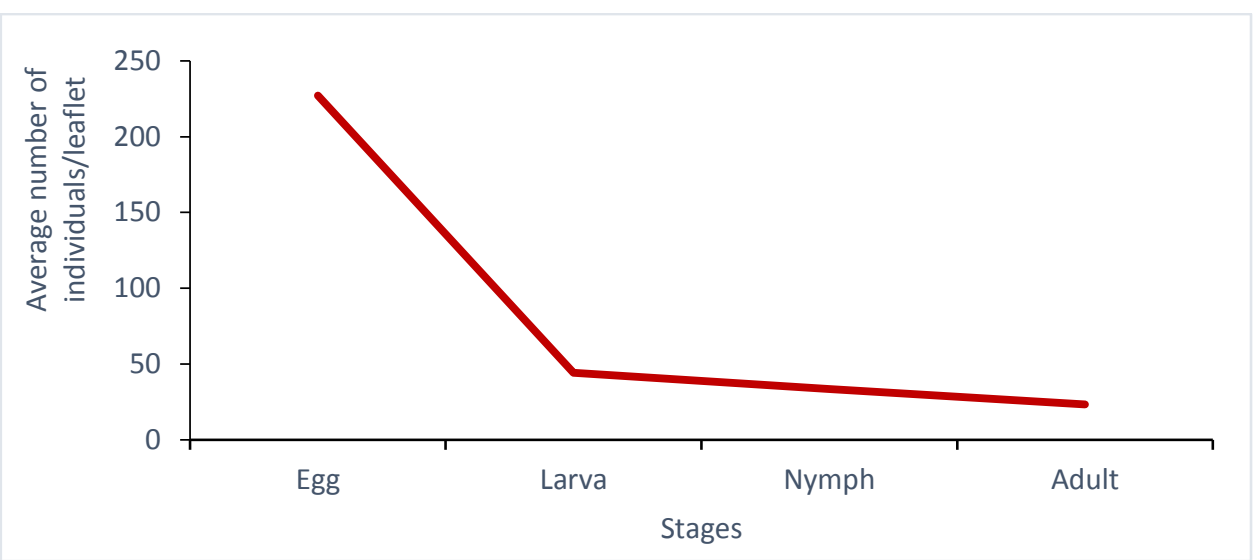

Figure 2: Evolution of the average number of individuals per leaflet according to the stages.

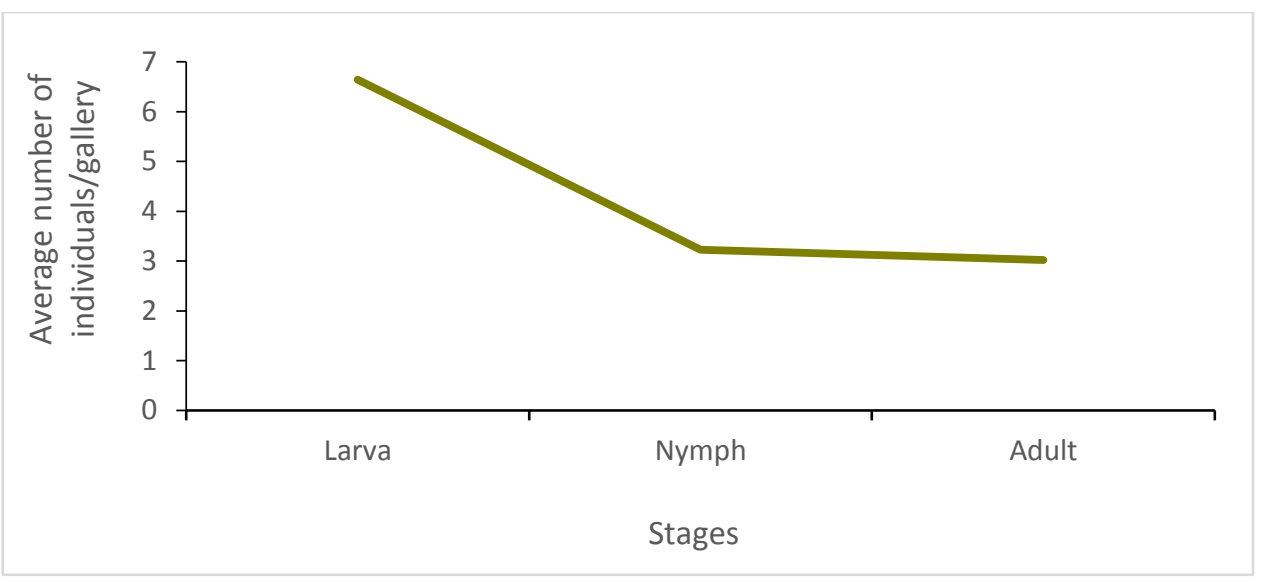

Figure 3: Evolution of the average number of individuals per gallery according to the stages.

Table 1: Average development time of C. lameensis.

\begin{tabular}{lc}
\hline Stages & Stages Development time (in days) \\
\hline Dpreco & $3.5 \pm 0.51$ \\
\hline Dpreop & $7 \pm 0.44$ \\
\hline Di & $20.5 \pm 1.11$ \\
\hline DL1 & $12.5 \pm 1.07$ \\
\hline DL2 & $9.5 \pm 0.96$ \\
\hline DL3 & $10.5 \pm 1.19$ \\
\hline DL4 & $14.5 \pm 1.08$ \\
\hline Dn & $13.5 \pm 0.86$ \\
\hline Dadi & $3 \pm 0.69$ \\
\hline Total cycle time & $94.5 \pm 7.94$ \\
\hline
\end{tabular}

Di : Average incubation time ; Dprecop : Average duration of pre-copulation ; Dpreop : Average duration of pre-oviposition ; DL1 : Average development time of the 1st larval stage ; DL2 : Average development time of the 2nd larval stage ; DL3: Average development time of the 3rd larval stage ; DL4 : Average development time of the 4th larval stage ; Dn : Average nymph development time ; Dadi : Average development time of internal adult. 
L1
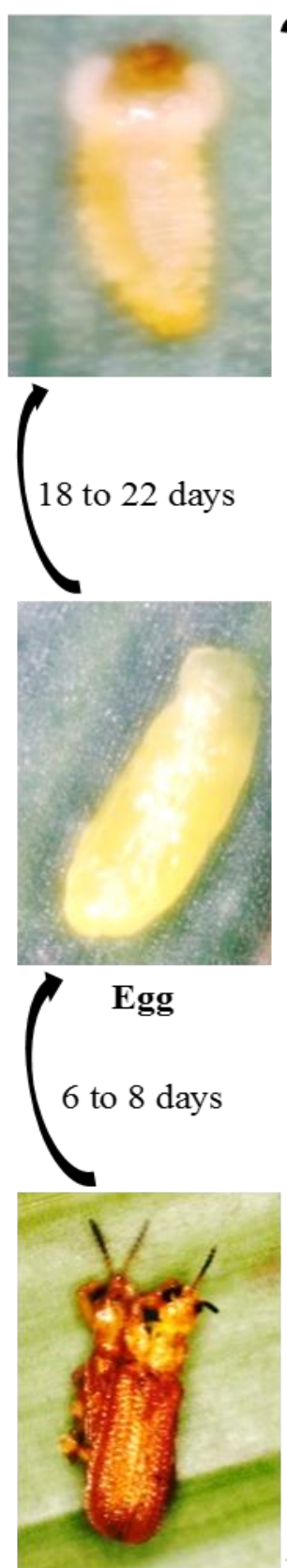

Copulation
L2
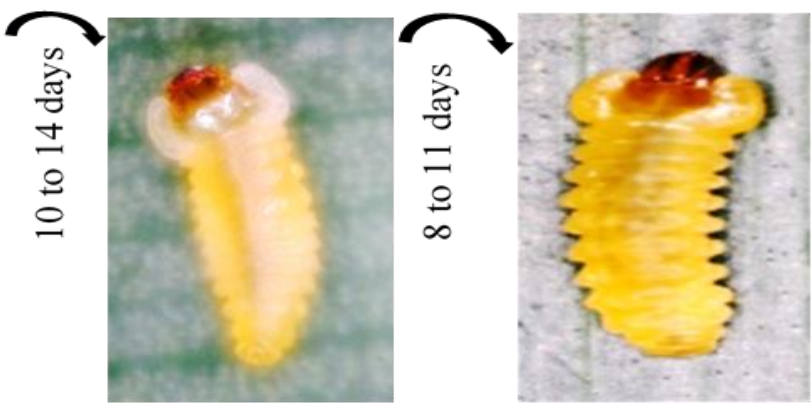

$28.08 \pm 0.79^{\circ} \mathrm{C}, 82 \pm 15.76 \% \mathrm{RH}$

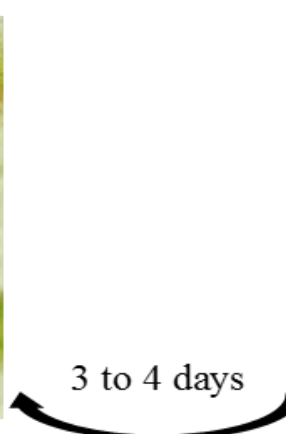

External adult
L4
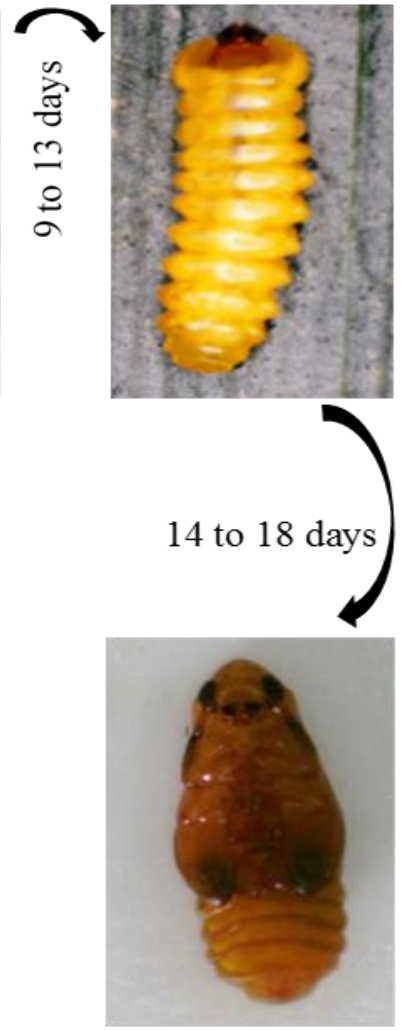

Nymph

12 to 15 jours
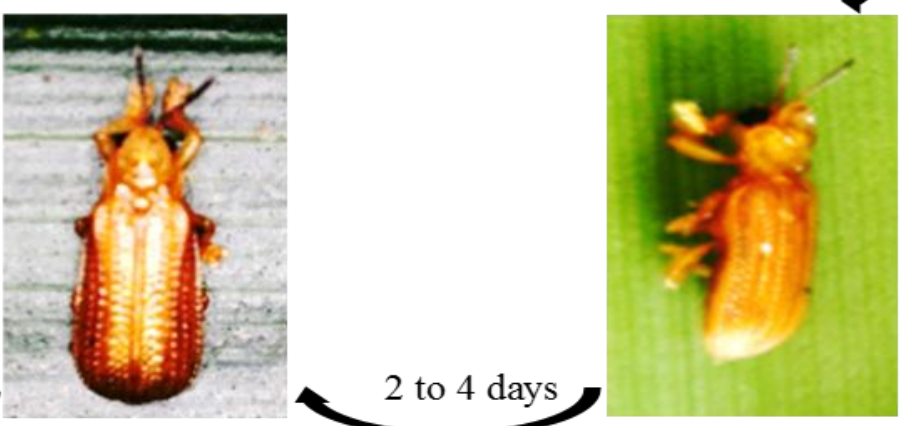

Internal adult

Figure 4: Development cycle of $C$. lameensis.

L1 : 1st larval stage, L2 : 2nd larval stage, L3 : 3rd larval stage, L4 : 4th larval stage, RH : Relative humidity. 


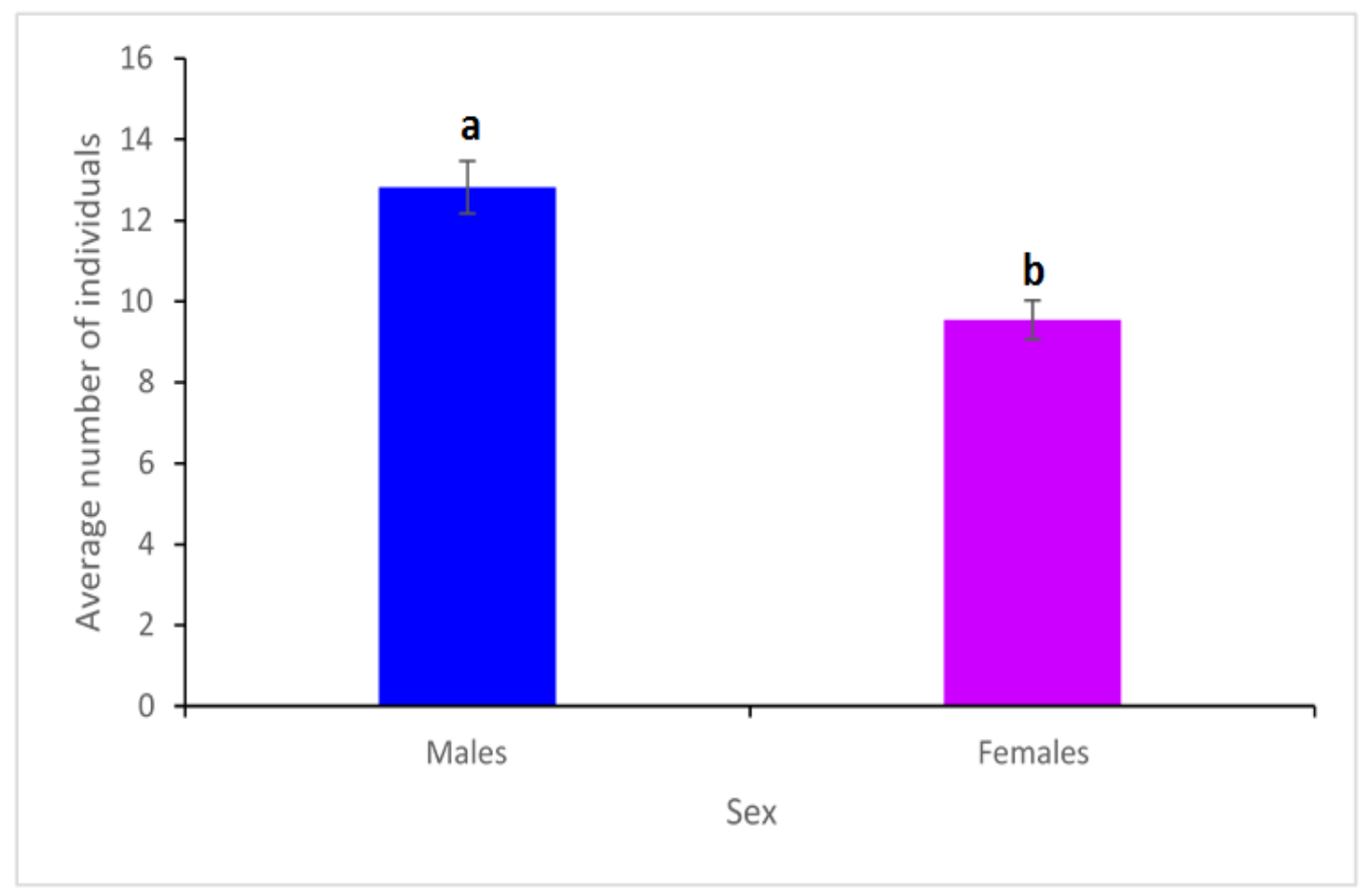

Figure 5: Average individuals number of $C$. lameensis according to sex. Histograms are statistically different at the $5 \%$ level.

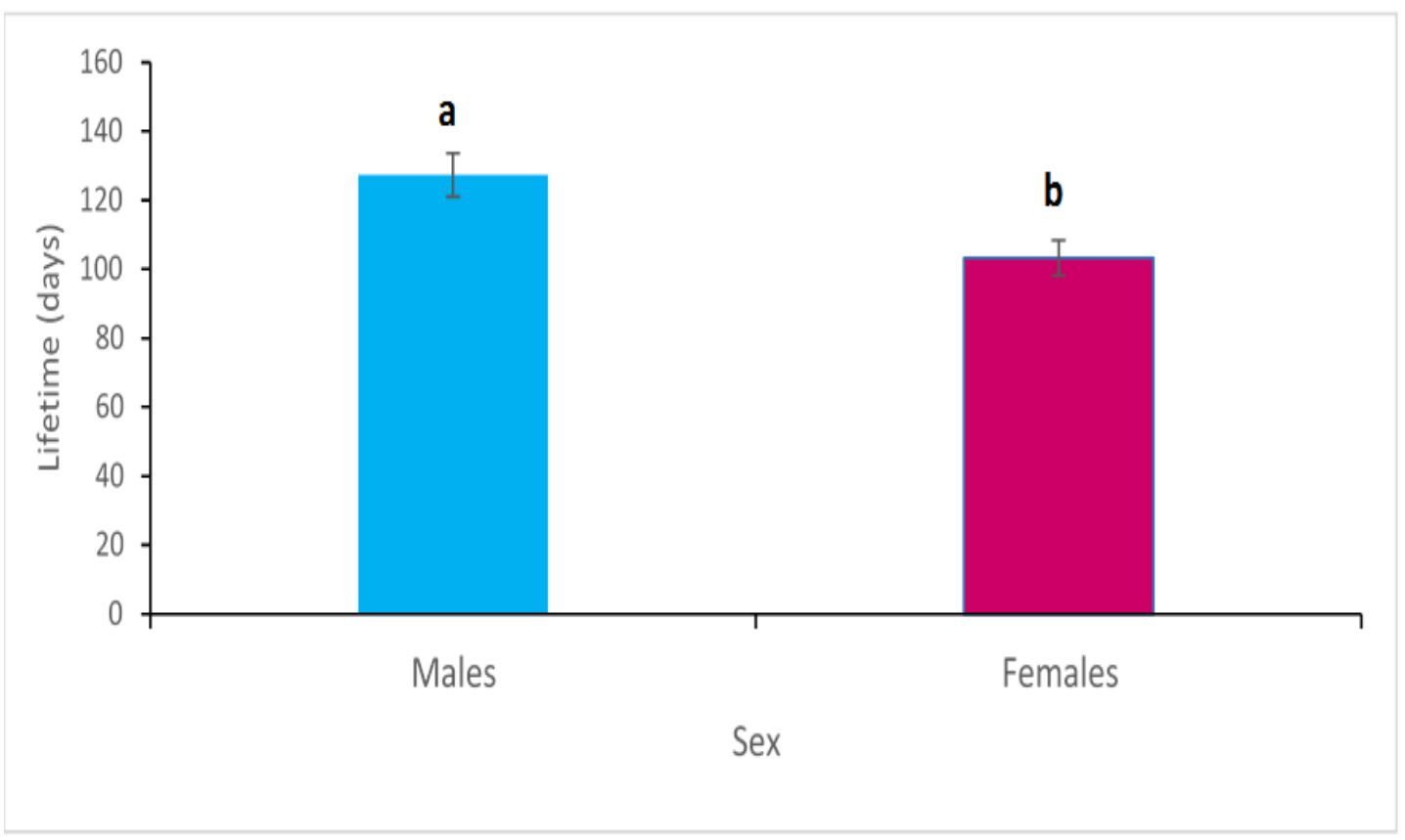

Figure 6: Lifetime of C. lameensis according to sex.

Histograms are statistically different at the 5\% level. 


\section{DISCUSSION}

During this study, the female of $C$. lameensis laid an average of $137.48 \pm 62.04$ eggs. The work of Mariau and Lecoustre (2000) on the role of eco-climatic and edaphic factors on field fertility of $C$. lameensis, showed that this pest can lay 56 to 400 eggs. This difference could be explained by a variation in temperature and humidity conditions. Indeed, our work was carried out at a temperature of $28.08 \pm 0.79^{\circ} \mathrm{C}$ with $82 \pm$ $15.76 \%$ Relative Humidity (RH), while those of Mariau and Lecoustre (2000) were carried out under different temperatures $\left(25.8^{\circ} \mathrm{C}\right.$ and $22.4^{\circ} \mathrm{C}$ ) and different relative humidity values (60\% RH and $80 \% \mathrm{RH})$. Thus, they showed that the fertility of $C$. lameensis is strongly influenced by temperature and relative humidity. Indeed, for two batches of $C$. lameensis having the same origin, the number of eggs laid was experimentally 117 eggs at $25.8^{\circ} \mathrm{C}$ against 56 eggs at $22.4^{\circ} \mathrm{C}$ and 206 eggs at $60 \%$ Relative humidity $(\mathrm{RH})$ versus 400 eggs at $80 \%$ RH.

In $C$. lameensis, the larva, nymph and internal adult live in galleries and each gallery may contain one or more individuals. This same observation was made by Koua et al. (2010), Tano (2012) and Konan et al. (2014) in this same insect. Similar results were obtained in Javeta pallida, with the difference that in this beetle, there is generally only one individual (larva or nymph or adult) per gallery, rarely more (Shameem et al., 2016).

The average number of $C$. lameensis individuals gradually declined from the egg stage to the adult stage. This suggests that there are mortality factors in this species, including the action of parasites. According to Mariau (2001), the stages (egg, larva and nymph) are attacked by numerous parasites whose development can cause certain eggs to dry out, thus reducing the number of larvae at hatching. These larvae obtained in turn are subject to the action of these parasites and decrease in number. This will result in obtaining a low number of nymphs. These nymphs are also victims of the action of parasites and decrease in number, resulting in a low number of adults. Kouakou et al. (2018) reported that in the species Elaeidobius Kamerunicus (Coleoptera:
Curculionidae), high humidities could favor the development of parasites or entomopathogenic fungi that harm the insect.

Coelaenomenodera lameensis has a holometabol-like development. Indeed, a complete metamorphosis is observed during its development. It occurs between egg and larva, between larva and nymph and between nymph and adult so that the morphological characteristics of these stages are totally different from each other. Shameem et al. (2016), studying the biology of Javeta pallida (Coleoptera, Chrysomelidae: Cassidinae) obtained similar results.

The length of the complete life cycle of C. lameensis averaged $94.5 \pm 7.94$ days, or approximately 3 months. Tano (2012), on the other hand, obtained a developmental duration of between $75.5 \pm 0.71$ and $83 \pm 1.41$ days. By comparing our results with those of this author, we can see that the cycle lengthened over time. This would be attributable to the temperature and hygrometry conditions which can vary from year to year. Indeed, the experimental conditions of this study were $28.08 \pm 0.79^{\circ} \mathrm{C}$ and $82 \pm 15.76 \%$ relative humidity while those of Tano (2012) were $27.76 \pm 0.98^{\circ} \mathrm{C}$ and 82.15 $\pm 2.03 \% \mathrm{RH}$. However, the difference between these temperature and humidity values and those in our study is not really big. This assumes that even a small variation in climatic factors can lead to a variation in the length of the life cycle. Traoré et al. (2018) reported that the development cycle of Maruca vitrata Fabricius (Lepidoptera: Crambidae) is longer at low temperatures and becomes short at high temperatures. Also, Minko (2009), had reported that in the mealy mealybug of cassava Phenacoccus manihoti (Homoptera: Pseudococcidae), the increase in temperature generally reflects a reduction in the duration of development, both embryonic and larval and therefore that of the complete life cycle. Thus, for temperatures between 20 and $30^{\circ} \mathrm{C}$, a variable duration was recorded from $15.29 \pm$ 1.06 to $6.15 \pm 0.56$ days for embryonic development, from $10.9 \pm 1.38$ at $5.47 \pm 0.66$ days for L1 larva, $7.87 \pm 1.17$ to $4.26 \pm 0.71$ days for L2 larva, $7.24 \pm 0.74$ to $3.85 \pm 0.86$ days for L3 larva, $7.47 \pm 0.96$ to $4.29 \pm 0.79$ days for L4 larva and $48.87 \pm 3.01$ to $23.99 \pm$ 
0.87 days for cycle full. Minko (2009) also reported that the durations of embryonic development and the percentage of hatching of this mealybug increase with humidity. On the other hand, humidity does not have a significant effect on the duration of development of stages and on the complete life cycle.

The sex ratio of $C$. lameensis was 1.34 \pm 0.25 in favor of males. And yet, in Elaeidobius Kamerinucus (Coleoptera: Curculionidae) (Tuo, 2013), Pseudotheraptus devastans (Heteroptera: Coreidae) (Doh, 2019) and Prosoestus scuptilis (Coleoptera: Curculionidae) (Tuo, 2013), and Prosoestus scuptilis (Coleoptera: Curculionidae) (Hala, 2020), he was in favor of the females. The variation in the sex ratio in favor of the male or female gender would certainly be due to agroecological factors (temperature and humidity), parameters that vary in time and space. Moumouni et al. (2013) reported in Niger that the sex ratio of cowpea weevil Callosobruschus maculatus (Coleoptera: Bruchidae) varies according to the agroecological origin of the strains. In fact, the sex ratio of this weevil was in favor of females for strains from the localities of Gaya (1.14) and Ayerou (1.05). On the other hand, he was in favor of the males for the strains coming from the localities of Maradi (0.78) and Tchintabaraden (0.81). Since temperature and humidity conditions can vary from one locality to another, the biological parameters of this weevil can also vary.

The average lifetime of $C$. lameensis was shorter in females $(103.24 \pm 10.25$ days $)$ than in males $(127.34 \pm 21.41$ days). Tano (2012) reached the same conclusion when studying the biology of this pest. These results are similar to those of N'guessan (2016) who obtained a shorter lifetime in females of Bactrocera dorsalis (Diptera: Tephritidae) (75.97 \pm 4.49 days) than in males $(82 \pm 5.82$ days) of this species. Similarly, Doh (2019) obtained a shorter lifetime of females of the coconut bug Pseudotheraptus devastans (Heteroptera: Coreidae) $(112.6 \pm 23.45$ days $)$ than that of males $(131.3 \pm 27.7$ days $)$. However, Tuo (2013) reported that females of Elaeidobius kamerunicus (Coleoptera:
Curculionidae) have a longer lifetime (31.22 \pm 6.47 days) than males $(27.96 \pm 2.99)$. The short lifetime observed in females is linked to the high energy they spend during egg laying as reported by Zannou (2000), Tano et al. (2011) and Tano (2012).

The sex ratio in favor of males, and the short lifetime of females of $C$. lameensis, could be considered as limiting factors in the reproduction of this species, since it is the females that lay the eggs from which to grow and will form new individuals to ensure the survival of the species. In fact, the fewer females there are in the population, the fewer reproduction cycles there will be and therefore new individuals. Likewise, the shorter their lifetime, the fewer reproductive cycles it could have.

\section{Conclusion}

During its development, $C$. lameensis passes successively through the egg, larva, nymph, internal adult and external adult stages. Four stages of larvae can be distinguished in this pest, with 4th instar larvae being the longest. The female lays an average of 137.48 \pm 62.04 eggs and the number of individuals gradually decreases from the egg stage to the adult stage. The average life cycle of $C$. lameensis was $94.5 \pm 7.94$ days with a sex ratio of $1.34 \pm 0.25$ in favor of males. The average lifetime of $C$. lameensis was shorter in females (103.24 \pm 10.25 days) than in males $(127.34 \pm$ 21.41 days). The control of all these biological parameters of $C$. lameensis could thus make it possible to better manage its populations through the implementation of several effective control strategies.

\section{COMPETING INTERESTS}

The authors declare that they have no competing interests.

\section{AUTHORS' CONTRIBUTIONS}

ACK participated in data collection, data analysis, and writing of the manuscript. AAMA participated in writing and editing the manuscript. NH conceived study and participated in data collection. AHN, HK, and KPK participated in writing and editing the manuscript. 


\section{ACKNOWLEDGMENTS}

The Interprofessional Association of the Oil Palm sector (AIPH) funded this work through the Interprofessional Fund for Agricultural Research and Advice (FIRCA). Also, the National Agronomic Research Center (CNRA) served as a framework for carrying out this work. We particularly thank these different structures.

\section{REFERENCES}

Aholoukpe H, Vissoh VP, Amadji G, Deleporte P, Dubos B, Nodichao L, Gglele Kakaï R, Chotte JL, Blavet D. 2013. Typologie des plantations villageoises de palmier à huile (Elaeis guineensis Jacq.) dans le département du Plateau au Bénin. Int. J. Biol. Chem. Sci., 7(3): $\quad 978-999 . \quad$ DOI: http://dx.doi.org/10.4314/ijbcs.v7i3.8

Akpesse AAM, Koua HK, Mora P, Miambi E. 2015. Enzyme profile of the oil palm (Elaeis guineensis Jacq) pest Coelaenomenodera lameensis Berti and Mariau (Coleoptera: Chrysomelidae, Hispinae) according to the different developpement stages. J. Oil. palm Res., 27(2) : 135-143.

Bessou C, Dubos B. 2020. Filière palmier à huile en Côte d'Ivoire: Analyse fonctionnelle et diagnostic agronomique. CIRAD-PERSYST N ${ }^{\circ}$ 2912, Montpellier, 42p.

Cucumel M. 2020. La filière palmier à huile en Côte d'Ivoire : Un condensé des enjeux du développement durable. FondationFarm, France, 23 p.

Doh F. 2019. Tolérance variétale et utilisation de biopesticides dans la lutte contre la punaise Pseudotheraptus devastans Distant (Heteroptera: Coreidae), ravageur du cocotier en Côte d'Ivoire. Thèse de Doctorat, Université Nangui Abrogoua, $112 \mathrm{p}$.

Hala KA. 2020. Bioécologie, dégâts, répartition de Prosoestus scuptilis et Prosoestus minor (Coleoptera, Curculionidae) dans les principales zones de production du palmier à huile (Elaeis guineensis Jacq.) en Côte d'Ivoire et recherche de méthodes de lutte pour l'amélioration du taux de nouaison. Thèse de Doctorat, Université Félix Houphouët Boigny, Côte d'Ivoire, $160 \mathrm{p}$.

Konan JN, Hala KA, Hala N, Konan E, Sekou D, Koné B, Koutou A. 2014. Évaluation de la sensibilité de sept clones de palmier à huile (Elaeis guineensis Jacq.) à Coelaenomenodera lameensis Berti et Mariau (Coleoptera, Chrysomelidae). $J$. Appl. Biosci., 82: 7460-7468. DOI: http://dx.doi.org/10.4314/jab.v82i1.5

Koua KH, Mathieu J, Seri-Kouassi PB, Tano Y, Mora P. 2010. Spatio-temporal distribution of the infestations of Coelaenomenodera lameensis Berti and Mariau (Coleoptera, Chrysomelidae) an oil palm tree (Elaeis guineensis Jacq.) pest in Toumanguié (Côte d'Ivoire). Sci. et Nat., 7(1): 1-10. DOI: 10.4314/scinat.v7i1.59908

Kouakou M, Hala N, Tuo Y, Hala KA, Douan BG, Dagnogo M, Koua KH. 2018. Influence du nombre d'inflorescences et de quelques facteurs climatiques sur l'abondance de Elaeidobius kamerunicus (Coleoptera: Curculionidae), principal pollinisateur du palmier à huile en Côte d'Ivoire. Int. J. Biol. Chem. Sci., 12(4): 1571-1582.

DOI: https://dx.doi.org/10.4314/ijbcs.v12i4.5.

Mariau D, Lecoustre R. 2000. Rôle des facteurs éco-climatiques et édaphiques sur la fécondité au champ de Coelaenomenadera lameensis, mineur des feuilles de Palmier à huile en Afrique de l'Ouest. International Journal of Tropical Insect Science, 20(1): 7-21. DOI : https://doi.org/10.1017/S1742758400017 781

Mariau D. 2001. Gestion des populations de Coelaenomenodera lameensis Berti et Mariau (Coleoptera, Chrysomelidae) en vue de la mise au point d'une stratégie de lutte raisonnée. Thèse de Doctorat, Ecole Nationale Supérieure d'Agronomie de Montpellier, France, 198 p.

Minko OD. 2009. Influence des facteurs écologiques (température et hygrométrie) 
sur le développement de la cochenille farineuse $\mathrm{du}$ manioc (Phenacoccus manihoti Matile-Ferrero, Homoptera : Pseudococcidae). Tropicultura, 27(1): 21-25.

Moumouni DA, Doumma A, Sembene M. 2013. Influence des zones agroécologiques sur les paramètres biologiques de Callosobruchus maculatus (Coleoptera-Bruchidea), ravageurs des graines du niébé (Vigna unguiculata Walp.) au Niger. Int. J. Biol. Chem. Sci., 7(5): 1866-1876. DOI: $10.4314 /$ ijbcs.v7i5.7

N'Guessan ENM. 2016. Dynamique des populations, activités comportementale et reproductrice de Bactrocera dorsalis Hendel 1912 et de Ceratitis cosyra Walker 1849 (Diptera : Tephritidae) dans trois zones agroécologiques de la Côte d'Ivoire. Thèse de Doctorat, Université Félix Houphouët-Boigny, $136 \mathrm{p}$.

Rival A. 2020. Huile de palme: Défis renouvelés de la durabilité. AgriTrop.Cirad, $17 \mathrm{p}$.

Shameem KM, Prathapan KD, Nasser M, Chaboo CS. 2016. Natural history of Javetia pallida Baly, 1958 on Phoenix palms in India (Chrysomelidae, Cassidinae, Coelaenomenoderinii). Zookeys., 597: 39-56. DOI: 10.3897/zookeys.597.6876

Tano DKC.2012. Contrôle des populations de Coelaenomenodera lameensis (Coleoptera : Chrysomelidae), principal ravageur du palmier à huile (Elaeis guineensis) aux moyens du Suneem $1 \%$ EC et d'extraits de plantes locales de Côte d'Ivoire. Thèse de Doctorat, Université Felix Houphouët-Boigny, Abidjan, Côted'Ivoire, $139 \mathrm{p}$.

Tano DKC, Seri-Kouassi BP, Aboua LRN. 2013. The effect of three plants aqueous extracts on feed intake and reproduction parameters of Coelaenomenodera lameensis Berti and Mariau (Coleoptera: Chrysomelidae) the pest of palm (Elaeis guineensis Jacq). J. Ani. Plant. Sci., 17: 2527-2539.

DOI: http://www.m.elewa.org/JAPS

Tano DKC, Séri-Kouassi BP, Ouali- N'goran SWM, Allou K. 2011. Etude de quelques paramètres biologiques de Pseudotheraptus devastans Distant (Heteroptera: Coreidae) sur les noix de Cocos nucifera L. de la variété PB121+ à la station Marc Delorme (Côte d'Ivoire). Sci. Nat., 8(1): 13-21. DOI : 10.4314/SCINAT. V8I1-2

Traore F, Waongo A, Dabire-binso C, Sanon A. 2018. Effet comparé de la température sur quelques paramètres biologiques de deux biotypes de Maruca vitrata Fabricius (Lepidoptera : Crambidae) en condition de laboratoire. Int. J. Biol. Chem. Sci., 12(5): 2152-2161. DOI: https://dx.doi.org/10.4314/ijbcs.v12i5.17

Tuo Y. 2013. Etat de l'entomofaune des inflorescences du palmier à huile en Côte d'Ivoire : Cas de la station CNRA de La Mé. Thèse de Doctorat, Université Félix Houphouët-Boigny, Abidjan, 192 p.

USDA. 2015. Oilseeds: World Markets and Trade. United States Departement of Agriculture, Foreign Agricultural Service, Office of Global Analysis, $38 \mathrm{p}$.

Zannou ET. 2000. Analyse de quelques paramètres biologiques pour une meilleure connaissance des capacités reproductrices d'une souche béninoise de Callosobruchus maculatus F. (Coleoptera : Bruchidae) : Caractérisation et importance de la diapause reproductrice chez les femelles du morphe voilier. Thèse de Doctorat, Université de Lomé, Togo, 147 p. 